\title{
AKTUELNOST INTEGRISANE MARKETING KOMUNIKACIJE
}

\author{
ACTUALITY OF INTEGRATED MARKETING \\ COMMUNICATION
}

\author{
Vladimir Stojanović \\ Poslovni i pravni fakultet „Union - Nikola Tesla“ Univerziteta, Beograd, \\ Srbija \\ CMESTE \\ JEL Category: D83, M31
}

\begin{abstract}
Apstrakt
Integrisane marketinške komunikacije predstavljaju koncept planiranja marketinških komunikacija koji prepoznaje dodatnu vrednost detaljnog plana, koji procenjuje strateške uloge niza komunikacijskih disciplina i kombinuje ove discipline kako bi obezbedio jasnoću, doslednost i maksimalan efekat komunikacija. Njen cilj je da utiče direktnim delovanjem na ponašanje izabranih ciljnih grupa, pri čemu se razmatraju sve vrste komunikacijskih kontakata koje bi budući kupci mogli ostvariti sa proizvodom/uslugom. To nedvosmisleno ukazuje da u tom procesu, integrisana marketinška komunikacija koristi sve vidove komunikacije, koji bi mogli biti relevantni i prihvatljivi za kupce. Sve veća potreba za integracijom komunikacijskih aktivnosti marketinga i odnosa s javnošću, koja je jedna od glavnih karakteristika savremenog poslovanja, može se, u najvećoj meri, zadovoljiti upravo usvajanjem koncepta integrisane marketing komunikacije. Posmatranje integrisane marketing komunikacije kao kontinualnog procesa, pruža mogućnost za praćenje i merenje efekata, u meri u kojoj je to ostvarljivo. Prepreke koje se najčešće javljaju u strategiji planiranja integrativnog komunikacionog marketinga i koji predstavljaju prepreke integraciji, uglavnom su internog karaktera, što znači da su u nadležnosti menadžmenta organizacije, tj. njihovog planiranog prevazilaženja. Korišćenje svih vrsta komunikacijskih sredstava podrazumeva da svaki medij kojim se jedna poruka može preneti, a koji je sposoban da dopre do ciljne publike i da proizvod ili uslugu predstavi u na najbolji mogući način. Cilj integrisane marketinške komunikacije je da poslata poruka uspešno stigne do ciljnih grupa, koristeći najprikladniji metod, odnosno kanal.
\end{abstract}

Ključne reči: menadžment, marketing, stejkholderi, kanali komunikacija, konkurentnost, profitabilnost.

\begin{abstract}
Integrated marketing communications are the concept of marketing communications planning that recognizes the added value of a detailed plan that evaluates the strategic roles of a range of communication disciplines and combines these disciplines to ensure clarity, consistency and maximum

Adresa autora:

Vladimir Stojanović

趣maestros@sbb.rs

communication effect. Its goal is to influence direct action on the behavior of selected target groups while considering all types of communication
\end{abstract}


contacts that future customers can accomplish with the product/service. This unambiguously indicates that in this process, integrated marketing communications use all types of communication that could be relevant and acceptable to customers. The growing need for the integration of communication activities of marketing and public relations, which is one of the main characteristics of the modern business, can be met by the adoption of the concept of integrated marketing communication. Observing integrated marketing communication as a continuous process, provides the ability to monitor and measure effects, to the extent that it is feasible. Obstacles that are most commonly encountered in the strategy of integrative communication marketing planning and which are preoccupied with integration are largely internal, which means that they are within the competence of the organization's management, their planned overcoming. Using all kinds of means of communication means that each medium by which one message can be transmitted, which is able to reach the target audience and present the product or service in the best possible way. The objective of integrated marketing communication is to send the message successfully to the target groups using the most appropriate method or channel.

Keywords: management, marketing, stakeholders, communication channels, competitiveness, profitability.

\section{UVOD}

Marketinška komunikacija predstavlja presudan aspekt sveukupnih marketinških napora jedne organizacije i odlučujući faktor njenog uspeha. (Shimp, 2000, str. 3, 23) Kotler navodi da "moderan marketing zahteva više od razvoja novog proizvoda, formiranje atraktivne cene i zalaganja da taj proces bude dostupan". Sama činjenica da se važnost marketing komunikacija svakim danom sve više povećava, upućuje nas na razumevanje Kotlerovog viđenja marketing komunikacije kao "sredstvo pomoću kojih kompanije pokušavaju da informišu, ubede podsete potrošače - direktno ili indirektno - o proizvodima i brendovima koje prodaju". (Kotler \& Keller, 2006, str. 536) Savremene organizacije, bez obzira da li su profitne ili neprofitne, koriste raspoložive različite oblike marketinške komunikacije, kako bi promovisale svoju ponudu i postigle svoje strategijski definisane ciljeve.

Osnovni cilj marketinške komunikacije je da bude aktuelna, što podrazumeva da se prava poruka saopšti na pravi način, pravim ljudima, na pravom mestu i u pravo vreme. Za većinu autora, miks marketinške komunikacije predstavlja sinonim za miks promocije, odnosno promotivni miks. Miks marketinške komunikacije zapravo predstavlja integrisani skup aktivnosti koje organizacija kombinuje, kako bi komunicirala sa svojim ciljnim grupama o svim bitnim faktorima koje utiču na poslovanje. U sadašnjim uslovima na tržištu najveći uticaj delovanja marketinške komunikacije može biti postignut ukoliko su svi elementi integralno zastupljeni.
Kada je reč o konceptu marketinške komunikacije, može se sa sigurnošću reći da on suštini predstavlja nešto obuhvatniji termin od promocije, a bazira se na argumentima koje je izneo Wayne DeLozier da svaki od instrumenata marketing miksa ima ulogu u procesu marketinške komunikacije, da su zapravo svi oni međusobno povezani i da svaki od njih u sebi nosi elemente marketinške komunikacije. (Jefkins, 1991)

Neosporna suština različitosti je zapravo zasnovana na osnovnim elementima marketing miksa (za proizvod, cenu, distribuciju, prodaju i promociju). To upravo znači da na ovom nivou podele, dizajnirano pakovanje proizvoda nije deo marketinga već pripada isključivo instrumentu proizvod, dok prodajno okruženje pripada instrumentu distribucija i prodaja i time se isključuju iz planiranja i realizacije instrumenta promocije. Drugim rečima, miks marketing komunikacije čine komunikacijski aspekti svakog od instrumenata marketing miksa. Jefkins, F. (1991) ukazuje na to da bi "marketing komunikacija trebalo da bude upravo ono što njen naziv govori. Ona sadrži sve vidove komunikacije koji imaju veze sa marketingom, i praktični su samo dok su deo niza."

\section{INTEGRISANA MARKETINŠKA KOMUNIKACIJA}

Pod nazivom integrisana marketing komunikacija većina autora, najkraće rečeno, podrazumeva potpuno usaglašavanje komunikacije sa stejkholderima, kroz različite medije i upotrebom različitih komunikacionih alata. Integrisanjem elemenata miksa marketinške komunikacije stvaraju se mogućnosti za poboljšanje efektivnosti 
ukupnog delovanja marketinške komunikacije. Povećanjem broja promotivnih aktivnosti jedne organizacije raste i potreba za njihovim koordiniranjem. Organizacija koordinira sve svoje promotivne aktivnosti, primenjujući sistem integrisane marketinške komunikacije, kako bi javnosti prenela poruku koja morta da bude uverljiva jer samo tako može da ostvari efekat koji će doneti bolju konkurentsku sliku kako o sebi, tako i o svojim proizvodima i uslugama. (Milisavljević, Maričić, \& Gligorijević, 2005, str. 540)

Osnovni cilj primene koncepta integrisane marketinške komunikacije je da se ostvari što bolje pozicioniranje organizacije i njenih proizvoda / usluga u svesti kupaca, a samim tim i do boljih poslovnih rezultata uvećanjem prodaje.

$U$ literaturi se najčešće susrećemo sa definisanjem integrisane marketinške komunikacije, po kojoj ona predstavlja objedinjene svih aktivnosti marketinške komunikacije, pa bi takom pojednostavljenom definisanju mogli da kažemo da integrisana marketinška komunikacija predstavlja proces integrisanja svih elemenata promotivnog miksa. Picton i Broderik u Knjizi Integrisana marketing komunikacija, navode malo širu definiciju citirajući njenog stvaraoca istraživača Bettsa sa saradnicima (Betts, Huntington, Pulford, \& Warnaby, 1995) da "integrisanu marketinšku komunikaciju čini strateški izbor elemenata marketinške komunikacije, koji će efektivno i ekonomično uticati na transakcije između organizacije i njenih postojećih i potencijalnih korisnika, klijenata, ili potrošača". (Pickton \& Broderick, 2001, str. 66-68; 284)

Filip Kotler, istaknuti teoretičar i istraživač marketinga, definiše integrisanu marketinšku komunikaciju kao koncept po kome kompanija maksimalno pažljivo integriše i koordiniše brojne komunikacijske kanale da bi poslala sasvim jasnu, doslednu i privlačnu poruku o organizaciji i njenim proizvodima. (Kotler P. , 1999)

Savremeni koncepta marketing komunikacije determinisan je mnogobrojnim faktorima koji se realno mogu javiti na tržištu. Navešćemo nekoliko značajnih faktora (Caywood, 1997):

- indiferentnost kupaca,

- oštrija prodajna konkurencija,

- tendencija usitnjavanje tržišta,
- mnogobrojni medijski varijeteti,

- dalja globalizacija tržišta,

- stalna unapređenja u oblasti elektronske komunikacije,

- nepredvidljiva pojava medijskih alternativa i dr.

Započinjanje od kupca, integrisana marketing komunikacija se jasno stavlja pod okrilje marketinga. Svi napori se inicijalno usmeravaju na identifikaciju kupaca i njegovih potreba i zahteva, da bi se ti impulsi slali kreatorima programa integrisane marketing komunikacije, kojima bi oni činili osnovu za odgovarajuće metode razvoja adekvatnih i efektnih programa integrisane marketing komunikacije.

Vrlo često je nemoguće izmeriti efekte i pojedinačnih aktivnosti marketing komunikacije, po čemu ona predstavlja vodeću marketinšku disciplinu, pa s tim u vezi je i nerealno očekivati precizne činjenice o efektima njihovih različitih kombinacija, posmatranih tokom vremena i $u$ različitim situacijama. Instrument koji je moguće koristiti u tu svrhu je tzv. profil procene stepena integracije aktivnosti marketing komunikacije koje se unose u određenu matricu. U matricu se unose numerički brojevi procene nivoa integracije po različitim dimenzijama integracije aktivnosti marketing komunikacije. Cilj je da se omogući sagledavanje ukupnog stepena integracije koji je postignut. Dobijen rezultat (stepen integracije) ne predstavlja objektivan rezultat merenja jer je zasnovan na subjektivnom ocenjivanju, pa je zbog toga neophodno uključiti većeg broja članova tima.

Prema M. Gonring-u, upravljanje integrisanom marketing komunikacijom podrazumeva planiranje i realizaciju sledećih aktivnosti (Grunig, 1992):

- Revizija pojedinih troškovnih stavki vezanih za komunikacijske aktivnosti organizacije;

- Razviti sistem ocenjivanja komunikacijskih aktivnosti;

- Razviti baze podataka u cilju razumevanja svih učesnika u procesu integrisane marketing komunikacije;

- Identifikovati sve kontaktne tačke organizacije i njenih ciljnih grupa;

- Analizirati interne i eksterne komunikacijske trendove koji mogu uticati na poslovanje organizacije; 
- Formirati poslovne i komunikacijske planove za svako lokalno tržište;

- Imenovati menadžera koji će biti nadležan i odgovoran za uverljivost komunikacijskih napora organizacije;

- Stvoriti kompatibilan sistem, harmoniju i kvalitet korišćenjem svih komunikacijskih instrumenata;

- Zaposliti samo timske "igrače" $i$

- Uključiti integrisanu marketing komunikaciju u menadžment procese.

Neophodan uslov za funkcionisanje integrisane marketing komunikacije čini više dimenzija integracije komunikacijskih aktivnosti:

- Po kategorizaciji na instrumente miksa marketing komunikacije (ekonomska propaganda, unapređenje podaje, lična prodaja, tržišni odnosi s javnošću, ekonomski publicitet, komunikacijske aktivnosti direktnog marketinga, pakovanje i prodajno okruženje).

- Po njihovom redosledu realizacije (od razmene informacija sa okruženjem, u fazi strategijskog planiranja, preko razmene informacija za potrebe razvoja samog proizvoda, do komunikacijskih akcija za podršku prodaji i u periodu održavanja odnosa sa kupcima).

- Po prenosnim kanalima (direktno i indirektno, lično i putem mas-medija, verbalno i neverbalno i dr.) .

- Po nosiocima (od vrhovnog menadžmenta do prodavaca $i$ isporučioca, kao i sa predstavnicima određenih agencija, institu-cija, konsultantskih i izvršnih organizacija i sl.)

\subsection{Optimalne kombinacije instrumenata komunikacionog miksa}

Mnogobrojni rizici globalnog tržišta neprestano utiču na sklop celokupnog miksa marketinških komunikacija. Menadžeri imaju na raspolaganje set komunikacijskim sredstvima, a njihova primena zavisiće okolnosti koje prevladavaju u datom trenutku. Ne izdvaja se jedan, jedinstveni, najbolji pristup organizaciji marketinške komunikacije, u postizanja integracije.

Utvrđivanje optimalne kombinacije instrumenata miksa marketinške komunikacije, najčešće zahteva kombinaciju sledećih faktora (Filipović \& Kostić, 2001, str. 248-249) (Kotler \& Keller, 2006): - finansijska sredstva, cena,

- karakteristike proizvoda/usluge,

- karakteristike ciljnog tržišta,

- postojeći odnosi sa kupcima.

- aktivnosti konkurencije;

- faza životnog ciklusa u kojoj se proizvod/usluga nalazi,

- poslovna politika organizacije, i - prisustvo organizacije na međunarodnom tržištu.

\subsection{Ograničenja u primeni integrisane marketinške komunikacije}

Menadžeri marketinškog komuniciranja na globalnim međunarodnim tržištima, suočavaju se sa drugom vrstom problema, koji isto tako mogu predstavljati prepreke i ograničenja u upotrebi programa integrisane marketinške komunikacije. Samim postojanje većeg broja odeljenja u okviru jedne korporacije, koja su zadužena za različite oblike promocije može predstavljati problem u implementaciji uspešnog programa marketinške komunikacije. Ceo proces može biti doveden u pitanje, ukoliko menadžer ne poseduje sposobnost planiranja i organizovanja, budući da te iste poslove postojeće specijalizovane agencije rade nezavisno jedna od druge. (Milisavljević, Maričić, \& Gligorijević, 2005, str. 540)

Može se reći da su integraciju instrumenata marketinške komunikacije inicirale upravo ovakve agencije, u trenutku kada su počele međusobno da se povezuju pred sve učestalijim zahtevima klijenata za efikasnijom promocijom i slanjem jedinstvene poruke o organizaciji i njenim proizvodima / uslugama. Promene u praksi marketing komunikacije Imajući u vidu da marketing komunikacija obuhvata mnogo različitih aktivnosti, samim tim ona traži mnogo različitih ljudi uključenih u proces marketing komunikacije. Uslov da bi svi ovi ljudi i sve aktivnosti dobro funkcionisali zajedno, potrebno je da budu planski integrisani. Potreba za redefinisanjem sistema planiranja i realizacije u sistemu tradicionalnog pristupa programu marketing komunikacije, koja rezultuje usva-janjem koncepta integrisane marketing komuni-kacije, zasnovana je na određenim promenama.

Neke od najistaknutijih su sledeće (Shimp, 2000):

1. Smanjenje poverenja u masovno medijsko reklamiranje Istraživanja pokazuju nagli pad 
poverenja ciljnog auditorijuma u ekonomsko propagandne poruke putem mas-medija, koje uslovljavaju potrebu za uvođenjem novih metoda $u$ proces planiranja marketing komunikacije, u cilju povećanja stepena uspešnosti konkretnih komunikacijskih aktivnosti, odnosno broj novo ostvarenih komunikacijskih kontakata sa sadašnjim i potencijalnim kupcima. To ni u kom slučaju ne znači da je medijsko reklamiranje gubi od svoje važnosti $i$ da ga samim tim trebalo povlačiti iz procesa marketing komunikacije, već znači neophodnost da i druge komunikacijske alternative treba pažljivo razmotriti, pre bezuslovnog $\mathrm{i}$ isključivog usvajanja masovnog medijskog reklamiranja. Nasuprot dosadašnjem tradicionalnom verovanju da je medijsko reklamiranje najefektivnije, što je vrlo često bio i uzrok svođenja marketing komunikacije na ekonomsku propagandu, mogu se uočiti nove tendencije davanje značaja ostalim instrumentima marketing komunikacija.

2. Povećanje pouzdanosti fokusirane komunikacije U razvijenim zemljama sve veći je broj kompanija koje su orijentisane na odnose sa kupcima, a svoje komunikacijske aktivnosti zasnivaju na relevantnim bazama podataka sadašnjih i potencijalnih kupaca. Na osnovu istraživanja dobijen je podatak o tome da čak $80 \%$ organizacija poseduje baze podataka o kupcima, što, predstavlja znatan potencijal za primenu koncepta fokusirane i personalizovane komunikacije.

3. Povećana konkurencija među agencijama za pružanje usluga marketing komunikacije. Uplivom mnogobrojnih agencija za pružanje usluga marketing komunikacije ukazuje se potreba za povećanjem konkurentnosti njihovih pojedinačnih ponuda. Njihove usko specijalizovane ponude gube smisao $u$ okruženju koje zahteva integraciju komunikacijskih aktivnosti. Sada je pred agencijama novi izazov da ponudom višestrukih usluga $i$ višestruku saradnju u primeni sistema integrisane marketing komunikacije.

4. Uvođenje analize profitabilnosti marketing komunikacije. Realizacija aktivnosti marketing komunikacije podrazumeva odbacivanje stihijskog pristupa već pristup planskim aktivnostima, koji zahteva neophodnost analize profitabilnosti $\mathrm{i}$ isplativosti precizno definisanih komunikacijskih napora.

Imperativ je odrediti koje od primenjenih aktivnosti marketing komunikacije vraćaju sprovedene investicije. To podrazumeva da Menadžeri zaduženi za upravljanje procesom marketing komunikacije moraju biti i finansijski odgovorni za svoje odluke.

Tržišni odnosi $\mathrm{s}$ javnošću. $\mathrm{Na}$ globalnom svetskom tržištu izuzetno velikog stepena konkurentnosti i uspostavljanja visokih standarda poslovanja, jedini način uspešnog rezultata u poslovanju organizacija je precizno diferenciranje javnosti i usmeravanje usko specificiranih i konkretizovanih poslovnih aktivnosti na svaku od ciljnih grupa. Nema dileme da najznačajniji koncept marketinških aktivnosti predstavlja razvoj fokusirane komunikacije.

Metodi i tehnike odnosa s javnošću našle su svoju primenu u uspostavljanju komunikacije između organizacije i tržišnih ciljnih grupa. Taj segment odnosa $s$ javnošću može se označiti kao tržišni odnosi s javnošću i definisati kao "proces planiranja, izvođenja i ocene programa, kojima se podstiče povećana nabavka i zadovoljstvo kupaca, kroz uspostavljanje komunikacije (razmene informacija i utisaka), kojom se kompanije i njihovi proizvodi poistovećuju sa potrebama, željama, brigama i interesima kupaca." (Rosenblat, Cheatham, \& Watt, 1977)

$\mathrm{Na}$ tržištima sa mnoštvom konkurencije koja nastoji pridobiti kupce sve agresivnijom marketing komunikacijom, prisutna je stalna tendencija traganja za proizvodima koji odudaraju od proseka. Pod takvim okolnostima, spontana, neusiljena i prijateljska komunikacija sa kupcima, sve više dobija na značaju. Neretko, iza relativno anonimne organizacije ili neprimećenog korporativnog identiteta može stajati visoko profitabilan proizvod sa dobro poznatim imidžom robne marke. Isto tako, uspešno izgrađen korporativni identitet i pozitivan korporativni imidž mogu biti potpuno neefikasni ukoliko su sami sebi cilj, bez rezultujuće prodaje proizvoda kome nedostaje određena reputacija na tržištu. (Grunig, 1992, str. 224)

Tehnike tržišnih odnosa s javnošću uključuju:

- pripremu obaveštenja o proizvodu; utvrđivanje plana za realizaciju saradnje sa 
medijima, kao posrednicima za ostvarivanje komunikacije sa kupcima;

- učestvovanje u sponzorstvima raznih manifestacija (sportskih, kulturnih, zabavnih, i sl.), sa akcentom na proizvod i u odnosu na ciljnu grupu kupaca;

- prisustvo proizvoda na sajmovima i izložbama; itd.

Instrumenti tržišnih odnosa $s$ javnošću imaju značajnu ulogu u integrisanoj marketing komunikaciji iz sledećih razloga (Caywood, 1997):

- aktivan i permanentan metodološki pristup segmentaciji javnosti;

- zasniva se se na dvosmernoj komunikaciji,

- proveren ekonomičan način stvaranja pozitivnog mišljenja i pogodne klime za prodaju,

- ima mogućnost da uveća efekat poruke, angažovanjem uticajnih i objektivnih pojedinaca i grupa, uključujući i medije,

- omogućava primenu širokog spektra taktika kojima se sigurno doseže do ciljnog tržišta,

- kupcu se prilazi direktno, preko različitih nemedijskih sredstava $\mathrm{i}$ taktika, počev od ostvarenja ličnih kontakata na seminarima i simpozijumima, do raznovrsnih upotreba alternativnih tehnologija,

- koristan je pri usmeravanju organizacije na pridobijanje konkurentne prednosti putem podržavanja društvenih kretanja,

- koristi se prilikom identifikacije društvenih pojava koje mogu da utiču na tržište konkretnog proizvoda ili usluge,

- može da utiče na donošenje ključnih marketinških odluka od javnog interesa,

- ima ključnu komunikacijsku ulogu u sprečavanju i/ili rešavanju kriznih situacija, koje mogu da dovedu do gubitka kupaca i određenih tržišnih pozicija,

- doprinosi uspostavljanju poverenja kupaca u bezbednost i efikasnost proizvoda,

- pruža veću mogućnost odnosima s javnošću da utiču, ne samo na to šta i kako organizacije govore o svojim proizvodima, već i na to kako i koliko efektno to rade i $\mathrm{dr}$.

Višestrukost potrebe za uključivanjem tržišnih odnosa s javnošću, na strategijskom nivou planiranja $\mathrm{i}$ realizacije programa integrisane marketing komunikacije, uključuje (Grunig, 1992):

- Kreiranje povoljne klime na tržištu, pre intenzivne ekonomsko-propagandna kampa- nja. Tržišni odnosi s javnošću koriste se za izgradnju svesti o proizvodu u javnosti mnogo pre nego što joj on postane raspoloživ. Najava novog proizvoda pruža jedinstvenu priliku za pridobijanje javnosti i "dramatizovanje" situacije oko uvođenja proizvoda. Uspešno predstavljanje naročito usluga, posredstvom tržišnih odnosa s javnošću, može da ima veliki uticaj na njihovu prodaju $U$ velikom broju slučajeva ponude usluga, sa ekonomskopropagan-dnom kampanjom ne treba počinjati, sve dok prodaja ne počne da opada. U prilog opravdanosti ovakvog pristupa su sve prisutniji primeri inverzije tradicionalnog marketing procesa, po kome je kupac najpre kupovao proizvod, a tek onda se uveravao u kvalitet njegovih karakteristika. Uvođenjem kupaca u proces razvoja novog proizvoda (najčešće putem Internet prezentacija) uspostavlja se komunikacija kojom se inicira zadovoljstvo kupca, mnogo pre njegove kupovine.

- Ključnu i neizostavnu ulogu tržišnih odnosa s javnošću u situacijama kada je, iz različitih razloga, izostavljena ekonomska propaganda. U nekim situacijama, organizacija nije u mogućnosti da izdvoji sredstva za ekonomsku propagandu i, u tom slučaju, "nosilac" programa integrisane marketing komunikacije su tržišni odnosi s javnošću. Postoje i situacije kada to nije primereno ni neophodno. $\mathrm{Na}$ primer, za usluge Univerziteta, mnogo delotvornije su aktivnosti tržišnih odnosa s javnošću, nego ekonomske propagande ili nekog drugog instrumenta integrisane marketing komunikacije.

Iniciranje i plasiranje drugih vesti, kada nema vesti 0 proizvodu. $U$ slučaju ponude uobičajenih proizvoda ili proizvoda sa jednostavnim obeležjima, teško je formulisati strategiju ekonomske propagande baziranu na inovaciji, koja bi rezultovala efikasnošću ekonomsko-propagandnih poruka i porastom prodaje. $U$ takvim slučajevima treba istražiti ostale mogućnosti u organizaciji i njenim aktivnostima I identifikovati izvore potencijalnih vesti. Uloga tržišnih odnosa s javnošću je jedinstvena i neizostavna.

- "Infiltriranje" teme poruke plasirane putem ostalih instrumenata marketing komunikacije (naročito ekonomske propagande i unapređenja prodaje) u život kupaca. Jedna 
od osnovnih uloga tržišnih odnosa s javnošću je obezbeđivanje stalne prisutnosti proizvoda, od predstavljanja, do njegovog predmetnog i funkcionalnog zastarevanja. $U$ nekim slučajevima, ide se i korak dalje i nastoji se da se proizvod pozicionira, ne samo $u$ svest kupaca, već i u način njihovog života.

- Osavremenjivanje programa marketing komunikacije. Tržišni odnosi s javnošću predstavljaju jedan o glavnih izazova savremenog poslovanja, a uključivanje njihovih aktivnosti neizostavno je u planiranju i realizaciji programa integrisane marketing komunikacije, koja, kao takva, takođe predstavlja posledicu osavremenjivanja koncepta marketing komunikacije.

- Izgradnja ličnih odnosa sa kupcima. Kao instrument koji svoje aktivnosti bazira pretežno na interaktivnoj dvosmernoj komunikaciji, tržišni odnosi $s$ javnošću doprinose stvaranju ličnih odnosa između organizacije i njenih kupaca. Neke od aktivnosti, čijim procesom sprovođenja se to postiže su: potenciranje same ličnosti kupca u pisanoj komunikaciji, pružanje korisnih ideja, informacija i odgovora, sećanje na važne datume za kupca i sl. Izgrađujući reputaciju prijatelja kupaca, organizacija je u mogućnosti da stvori klimu prihvatanja svojih ekonomskopropagandnih poruka i samih proizvoda. Ovaj koncept je naročito značajan $u$ integrisanim marketing komunikacijama i pod uslovima koji vladaju na tržištu, koji utiču na to da mnogo manje napora i novca treba uložiti da bi se zadržao postojeći kupac, nego da bi se pridobio novi.

- Vršenje uticaja na lidere u stvaranju javnog mnjenja. Dok su napori ekonomske propagande usmereni skoro isključivo na kupce, ciljne grupe i pojedinci tržišnih odnosa $s$ javnošću su često i oni koji mogu uticati na povećanje prodaje.

- Iniciranje nepristrasnog iznošenja prednosti novog proizvoda Jedna od najefektivnijih aktivnosti tržišnih odnosa $s$ javnošću odnosi se na iniciranje objektivnih predloga i komentara u vezi nabavke novog proizvoda ili novootkrivenih pogodnosti starih.

- Demonstriranje društvene odgovornosti i izgradnja poverenja kod kupaca Generalno, odnosi s javnošću su kvalifikovani za usvajanje $\mathrm{i}$ ispoljavanje društvene odgovo- rnosti. Ubacivanjem ove poslovne karakteristike u deo poslovanja sa tržištem, ujedinjavaju se interesi organizacije i društva sa interesima kupaca. Ljudi žele da posluju sa organizacijama koje poznaju i kojima veruju.

- Pružanje podrške kupcu pri kupovini proizvoda u kriznim situacijama Zadatak odnosa s javnošću u kriznim situacijama je da se organizacija izbavi iz krizne situacije. Krizne situacije koje su zadesile mnoge organizacije, uticale su na stvaranje svesti o postojanju rizika u poslovanju.

\section{ZAKLJUČAK}

Savremeno poslovno okruženje karakteriše dinamičan miks konstantno rastuće konkurentnosti, novih kanala komunikacije i odnosa, promena stavova potrošača, povećano interesovanje za razumevanje njihovog ponašanja $i$ potrebe da se agresivnije i brže reaguje na promene koje nastaju na tržištu. Potrošači su postali promišljeniji, informisaniji, svesniji odnosa troškovi-vrednost, teško zabo-ravljaju, zahtevniji su, a samim tim i manje lojalni. U ovakvim uslovima poslovanja izazov je ne samo postići zadovoljstvo potrošača, već to pretočiti $u$ dugotrajnu lojalnost.

Uspeh koncepta upravljanja odnosima sa potrošačima ogleda se u sinergetskom efektu koji se postiže zadovoljavanjem dva kriterijuma: koncepcijskog koji pretpostavlja da je strategija preduzeća usmerena na pojedinačni pristup potrošačima i tehničkog koji podrazumeva primenu najsavremenije tehnologije, automati-zaciju marketinških procesa, efikasno upravljanje podacima i kampanjama.

Dobro implementirano upravljanje odnosima sa potrošačima podrazumeva skup: strateške vizije, maksimiziranja vrednosti za potrošače, korišćenja CRN aplikacija $i$ ispunjenja očekivanja $i$ postizanja efekta zadovoljstva.

Osnov za izgradnju dugoročnog i stabilnog partnerskog odnosa je dobro poznavanje svih strana u odnosu. Preduzeća, preduzimanjem inicijative za proučavanje, dizajniranje i implementaciju jedinstvenog identifikacionog sistema, omogućuju sebi da bolje upravljaju odnosima sa potrošačima.

Svi potrošači ne zaslužuju isti tretman. Najvredniji potrošači zaslužuju i najbolji tretman. Ako se 
prema najvrednijim potrošačima ponaša kao prema svima drugima, preduzeće može da očekuje da će se i oni ponašati na isti način prema njemu. Zadatak marketara je da, koristeći različite metode za diferenciranje, identifikuje svoje najbolje kupce i da sa njima održava neprekidnu i personalizovanu komunikaciju. Svakim danom sve više jača svest o tome da jedna organizacija mora da se obraća na određen način, kako kupcima, tako i ostalim ciljnim grupama iz svog okruženja koje, posredno ili neposredno, utiču na proces donošenja odluke o kupovini

$\mathrm{U}$ procesu utvrđivanja programa integrisane marketing komunikacije neophodno je imati u vidu njena osnovna obeležja: uticanje na ponašanje kupaca; započinjanje od kupca; korišćenje svih vrsta komunikacijskih sredstava; dostizanje sinergije i izgrađivanje odnosa. Jedino one komunikacijske aktivnosti od kojih se očekuje uspostavljanje dugoročnih efekata, za razliku od obezbeđivanja samog čina prodaje, su opravdane. Uspešan plan integrisane marketing komunikacije mora za osnovni cilj da postavi zadovoljenje kupčeve potrebe za određenom vrednošću.

Dostizanje sinergije predstavlja nezaobilazno mesto u definisanju integrisane marketinške komunikacije koja počiva na jedinstvenoj poruci koja se mora dosledno ponavljati svaki put kada brend dođe $\mathrm{u}$ kontakt sa ciljnom publikom. Uspostavljanje i održavanje odnosa je verovanje da uspešna marketinška komunikacija zahteva negovanje odnosa između organizacije i kupaca.

Veoma važnu karakteristiku integrisane marketing komunikacije predstavlja variranje stepena integracije, od nekoliko uobičajenih aktivnosti manjeg broja instrumenata marketing komunikacije, do razvoja programa komunikacijskih kampanja (sa uključivanjem velikog broja komunikacijskih aktivnosti svih instrumenata marketing komunikacije prema svim dimenzijama), čak i do razvoja i koordinacije više komunikacijskih kampanja, sa ciljem da se ostvare strategijski ciljevi na duži vremenski period i u odnosu na veći broj ciljnih grupa. Stepen integracije može se kretati od potpuno odvojenih $\mathrm{i}$ nezavisnih do potpuno integrisanih aktivnosti marketing komunikacije.

Prema dosadašnjim istraživanjima postojeća i nova ograničenja primene integrisanog marketinga komunikacijama leži pre svega $U$ otporu prema promenama, u velikom obimu aktivnosti, nerazvijenosti horizontalnih komunikacija, decentralizaciji odlučivanja, problemu merenja efekata integrisane marketinške komunikacije, potrebi za drugačijim vizijom organizacije koja bi se usmerila na njegovu primenu i slično.

\section{CITIRANA DELA}

Betts, P., Huntington, A., Pulford, A., \& Warnaby, G. (1995). Marketing Communications Strategy, II part. London: BPP Publishing

Caywood, L. (1997). The Handbook of Strategic Public Relations \& Integrated Communications. New York: McGraw-Hill.

Filipović, V., \& Kostić, M. (2001). Marketinig menadžment: Teorija i praksa. Beograd: FON Menadžment.

Grunig, J. (1992). Excellence in Public Relations and Communication Management. Lawrence Erlbaum. Jefkins, F. (1991). Modern Marketing Communications. London: Blackie \& Sons.

Kotler, P. (1999). Boards Should Tune in to Corporate Marketing Programs. Directorship, 25(7), 12-13, 19.

Kotler, P., \& Keller, K. (2006). Marketing menadžment. Beograd: Data Status.

Milisavljević, M., Maričić, B., \& Gligorijević, M. (2005). Osnovi marketinga. Beograd: Centar za izdavačku delatnost Ekonomskog fakulteta.

Pickton, D., \& Broderick, A. (2001). Integrated Marketing Communications. London: Prentice Hall.

Rosenblat, S., Cheatham, T., \& Watt, J. (1977). Communication in Business. New Jersey: Prentice Hall. 
Shimp, T. (2000). Advertising Promotion: Supplemental Aspects of Integrated Marketing Communications. Fort Worth: The Dryden Press.

Datum prve prijave:

07.03.2018.

Datum prijema korigovanog članka:

20.07.2018.

Datum prihvatanja članka:

05.09.2018.

Kako citirati ovaj rad? / How to cite this article?

Style - APA Sixth Edition:

Stojanović, V. (2018, 10 15). Aktuelnost integrisane marketing komunikacije. (Z. Čekerevac, Ur.) FBIM Transactions, 6(2), 171-179. doi:10.12709/fbim.06.06.02.17

Style - Chicago Sixteenth Edition:

Stojanović, Vladimir. 2018. „Aktuelnost integrisane marketing komunikacije.“ Urednik Zoran Čekerevac. FBIM Transactions (MESTE) 6 (2): 171-179. doi:10.12709/fbim.06.06.02.17.

Style - GOST Name Sort:

Stojanović Vladimir Aktuelnost integrisane marketing komunikacije [Časopis] // FBIM Transactions / ur. Čekerevac Zoran. - Beograd : MESTE, 1510 2018. - 2 : T. 6. - str. 171-179.

Style - Harvard Anglia:

Stojanović, V., 2018. Aktuelnost integrisane marketing komunikacije. FBIM Transactions, 15 10, 6(2), pp. 171-179.

Style - ISO 690 Numerical Reference:

Aktuelnost integrisane marketing komunikacije. Stojanović, Vladimir. [ur.] Zoran Čekerevac. 2, Beograd : MESTE, 1510 2018, FBIM Transactions, T. 6, str. 171-179. 